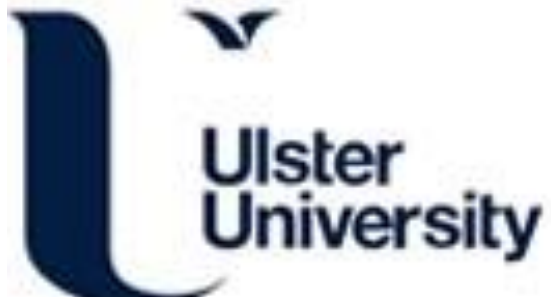

\section{Engineering Study of Tidal Stream Renewable Energy Generation and Visualization: Issues of Process Modelling and Implementation}

Harrison, J., \& Uhomoibhi, J. (2016). Engineering Study of Tidal Stream Renewable Energy Generation and Visualization: Issues of Process Modelling and Implementation. In Unknown Host Publication Association for Computing Machinery.

Link to publication record in Ulster University Research Portal

Published in:

Unknown Host Publication

Publication Status:

Published (in print/issue): 07/06/2016

\section{Document Version}

Author Accepted version

\section{General rights}

Copyright for the publications made accessible via Ulster University's Research Portal is retained by the author(s) and / or other copyright owners and it is a condition of accessing these publications that users recognise and abide by the legal requirements associated with these rights.

\section{Take down policy}

The Research Portal is Ulster University's institutional repository that provides access to Ulster's research outputs. Every effort has been made to ensure that content in the Research Portal does not infringe any person's rights, or applicable UK laws. If you discover content in the Research Portal that you believe breaches copyright or violates any law, please contact pure-support@ulster.ac.uk. 


\section{Engineering Study of Tidal Stream Renewable Energy Generation and Visualization: Issues of Process Modelling and Implementation}

\author{
J. Harrison \\ Faculty of Computing and Engineering \\ Ulster University, \\ Northern Ireland, UK \\ hayes-p4@email.ulster.ac.uk
}

\author{
J. O. Uhomoibhi \\ Faculty of Computing and Engineering \\ Ulster University \\ Northern Ireland, UK \\ j.uhomoibhi@ulster.ac.uk
}

\begin{abstract}
Tidal stream energy has the potential to make a significant contribution to the UK energy mix over the coming years. Accurate modelling and visualisation of both tidal resource and array layout will enhance understanding of in stream tidal behaviour leading to improvements in site identification and optimal positioning of individual turbines, and a realistic representation of blade loading conditions will aid designers and manufacturers in creating more robust devices and improve survivability.

The main barriers to large scale deployments of tidal arrays are the costs associated with manufacturing, installation and maintenance, therefore presently tidal energy is not competitive on cost with more established renewable technologies. Opportunities do exist to reduce costs and this technology can become competitive in the long term, however improved understanding of both environmental conditions and device behaviour is need to achieve this.

The ability to visual represent realistic behaviours will assist both industry and academics during resource modelling, site selection, selecting optimal array configurations and the design and manufacture of devices. It is in the interest of all practitioners involved in tidal stream energy to develop robust models which can reliably simulate real world conditions and enhance understanding of tidal processes, flow regimes and device survivability issues.
\end{abstract}

\section{Keywords}

Tidal stream energy, tidal turbines, tidal resource, visualisation, modelling

Permission to make digital or hard copies of all or part of this work for personal or classroom use is granted without fee provided that copies are not made or distributed for profit or commercial advantage and that copies bear this notice and the full citation on the first page. Copyrights for components of this work owned by others than ACM must be honored. Abstracting with credit is permitted. To copy otherwise, or republish, to post on servers or to redistribute to lists, requires prior specific permission and/or a fee. Request permissions from permissions@acm.org.

AVI 2016 Bari, Italy

c 2016 ACM. ISBN 978-1-4503-2138-9...\$15.00

DOI: $10.1145 / 1235$

\section{INTRODUCTION}

$\mathbf{R}$ ENEWABLE energy generation is growing in relevance $\mathbf{R}_{\text {due to the dual issues of continuing global warming and }}$ national security of electrical supply. A largely untapped potential resource is ocean energy which has the global potential to supply $170 \mathrm{TW}$ of electricity annually [1]. Of the currently available technologies to extract energy from the oceans only tidal range, which takes advantage of the vertical height difference between high and low tide, is at a mature stage of development [2]. A nascent alternative tidal technology exists which seeks to exploit horizontal fluid motion and is less intrusive than tidal range installations [3]. In stream tidal turbines and operates using the same basic principle as a wind turbine using seawater as the operating fluid rather than wind [4].

Tidal science is a developed field of study and the predictable nature of tidal motions overcomes stochastic issues faced by other renewable technologies, most notably wind and wave [5]. Predictability provides an advantage not only for grid management but also for accurate financial forecasting which is a key obstacle to the widespread installation of tidal stream turbine arrays [1].

Within the UK there is a desire to progress deployment of tidal stream technology and the Crown Estate, responsible for the seabed around the UK, has leased 26 zones suitable for tidal stream arrays. If these projects are all realised installed tidal stream capacity in the UK could reach 1200 MW [7].

\section{The COST OF OCEAN ENERgY}

Cost is seen as a major barrier to the wide scale deployment of ocean energy technology [8]. In order to improve investor confidence accurate resource assessment and forecasting models are required [7]. 


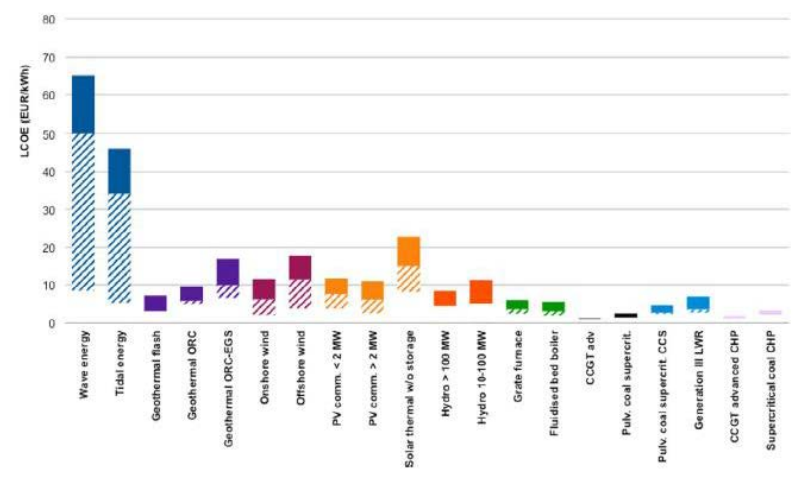

Fig. 1. Cost of Ocean Energy (Blue LHS of chart) vs other forms of electricity generation [9]

Cost reduction should be a target for the in stream tidal energy industry and reliable visual models for resource assessment and assessing the impact of turbine arrays on flow regimes should be developed. These could help to eliminate the current dependence on costly and time consuming empirical data collection.

There is also a need to improve device manufacturing techniques, accurate modelling of blade loading conditions will expedite blade and tower design consensus thus enabling greater supply chain competition. While models which accurately portray the cyclic nature of tidal loading will help to improve design for survivability and improve understanding regarding the detrimental effects of seawater ingress, particularly when designing with composite materials.

\section{RESOURCE ASSESSMENT}

\subsection{Current Guidelines}

In general, the most promising areas are found in ocean channels or straights where tidal flow is forced through a narrow cross section e.g. the Pentland Firth (Scotland) or Alderney (English Channel). Using Fig. 2. [10] it is possible to identify those sites around the UK where tidal flow velocities are greatest, these are the most attractive sites for development.

There is also a challenge when classifying the tidal velocity at a particular site as velocities will vary within the water column and across the cross section due to local bathymetry [11], therefore an average velocity is not sufficiently accurate to allow a developer to position turbines. For the reasons outlined above the European Marine Energy Centre (EMEC) have produced guidelines for resource assessment which recommend a developer conduct extensive onsite measurements when identifying a potential tidal site [12].

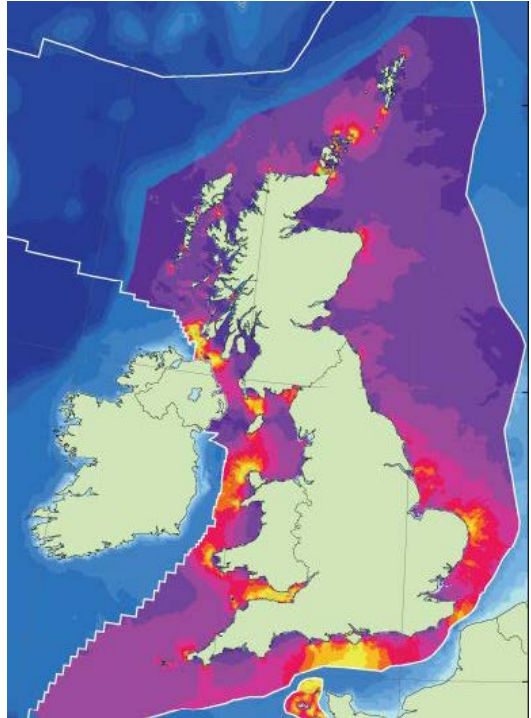

Fig. 2. Peak Flow for a Mean Spring Tide (areas in yellow have high velocity flow i.e. $>2 \mathrm{~m} / \mathrm{s}$ )

A challenge posed by the approach of EMEC is the time consuming and expensive installation of measurement apparatus. The development of advanced models to quickly and accurately predict tidal flows will benefit both site developers and academics by allowing the analysis of a greater number of potential sites without the need for extensive onsite measurements.

Velocity is of interest because the power output of a tidal turbine is related to the cube of water velocity, the power available at the rotor is found from,

$$
P_{t}=\frac{\rho \cdot A_{r} \cdot v^{3}}{2}
$$

Where Pt is the power available at the turbine rotor (W), $\rho$ is the density of seawater $(\mathrm{kg} / \mathrm{m} 3), \mathrm{Ar}$ is the swept area of the rotor blades $(\mathrm{m} 2)$ and $\mathrm{v} 3$ is the velocity of the seawater (m/s) passing through Ar.

There are a number of observers who highlight that looking purely at maximum flow velocities during the site selection process is superficial [13], these authors encourage a leasing strategy which reflects the need for phase diversity between tidal sites in order to provide a firm supply of electrical energy onto the national grid. 


\subsection{Tidal Range Data \& Tidal Charts}

In order to develop the required models, without using onsite measurements, available tidal range data and published surface tidal velocity charts should be exploited. Studies have been conducted [15], which seek to determine flow velocity using conservation of mass methods. The principle is, the tidal volume which flows into a body of water must have come through a channel which connects that body with the ocean.

A review of tidal charts reveals that the Irish Sea fills from both the north and south simultaneously, therefore the total height gained, as measured by onshore tidal range monitors, must have entered from these two channels (high tide). The tide then exits simultaneously through the same two channels resulting in a lower sea level (low tide). This cycle of high and low tide is repeated twice every day due to strongly semidiurnal tidal behaviour in the region with maximum (spring) and minimum (neap) tides occurring on a biweekly cycle.
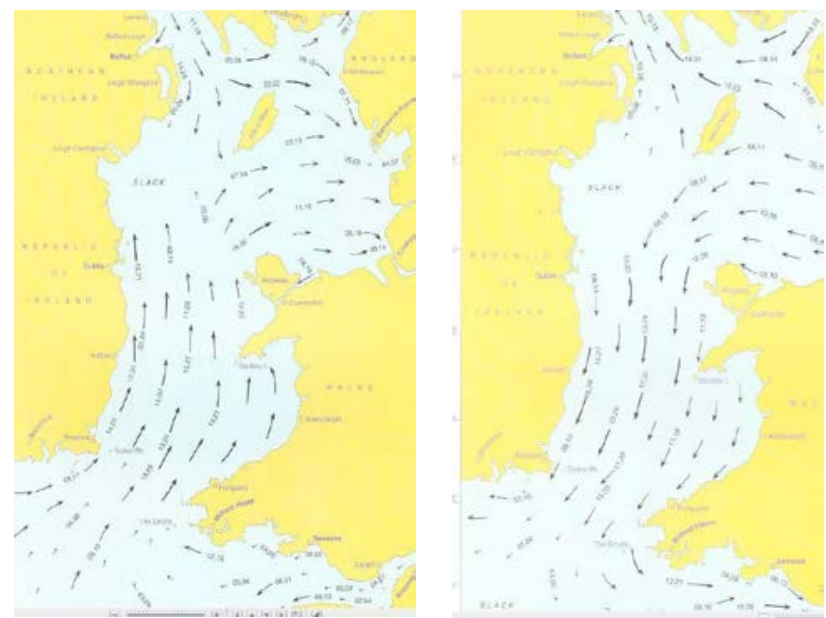

Fig. 3. Tidal flow in and out of the Irish Sea (source http://www.visitmyharbour.com/articles )

The ability to accurately visualise this flow enables a greater understanding of tidal behaviour and of the mathematics required to describe it. Both tidal range and tidal flow exhibit sinusoidal behaviour, as a result the volume of water which flows during a tidal cycle ranges from a maximum value at peak flow to zero during periods of slack water. In order to describe something which changes over time differential calculus is the most appropriate tool.

Vennell developed the relationship,

$$
A_{B} * \frac{d h}{d t}=Q
$$

Where $\mathrm{Q}$ is the volumetric flow $(\mathrm{m} 3 / \mathrm{s})$ required to rise the water level by $\mathrm{h}(\mathrm{m})$ in the body of water $\mathrm{AB}(\mathrm{m} 2)$. This simple relationship can be used to calculate volumetric flow through a channel which connects an enclosed body of water with the ocean and was developed to analyse a Norwegian Fjord. known, requires only accurate information regarding channel bathymetry and seafloor composition. NASA's satellites have accurately measured the earth's surface and ocean contours with the files being publically available and coefficient of friction is known for many seafloor types. It can only be a matter of time before models of tidal flow are developed which are sufficiently accurate to eliminate the current need for extensive onsite data collection.

\section{ARRAY LAYOUT}

In order to maximise the potential of high energy tidal sites it is likely that turbines will be grouped together into arrays, much in the same way wind turbines are often grouped together to form wind farms. Tidal arrays will face challenges due to their harsh operating environment and the loads created by a dense operating fluid.

\subsection{Wake Interactions}

Visual models which show wake interactions will be of great importance to tidal site developers as the available resource at each turbine can be significantly affected by any upstream turbines [16]. The effect is not always negative and studies suggest it is possible to exceed the Betz limit when siting a turbine within a tidal array due to the venturi effect of funnelling water between turbines [17], and while this could lead to greater output it will also lead to greater loads being experienced at the rotor blades. Any induced wake effect will be a compromise between maximum output and device survivability.

\subsection{Blade Behaviour}

Due to the significant loads created by seawater, blade designs and manufacturing methods will be a crucial aspect of maintaining device performance during operation.

Fluctuations in water velocity create much greater loads than those experienced in wind turbines. In order to prevent damage to blades it is important to develop increased understanding of blade deformation and vibration in order to improve modelling and simulation leading to improved blade designs.

Current studies are considering whether to allow turbine blades to flex under stress before reaching their optimal design [18] such research exposes the high level of concern over loading conditions for turbines placed in the open ocean. 
An accurate model which can visually represent realistic conditions at sea would be invaluable for design and R\&D practitioners, and would permit reliable simulations which are much less costly and time consuming than sea trials or other physical testing regimes.

\subsection{Sediment Transport}

A potential adverse environmental impact of installing a tidal array is the effect on local sediment transport due to a reduction in flow velocity. Modelling work has been conducted in the Pentland Firth where a number of tidal arrays are planned to be installed. A major challenge when investigating the possible localised impacts of a tidal array is a lack of commercial scale developments and at present there are no sizable tidal stream installations anywhere in the world, as a result it is likely that the first sites to be developed will be monitored extensively to ascertain environmental impacts.

It is difficult at present to imagine a model which could accurately simulate all environmental effects of reduced tidal flow and channel blockage, however a visual model to predict regular issues such as sediment transport or more stochastic events i.e. marine megafauna interaction may be possible in the future with more practical experience and monitoring of tidal stream arrays.

\section{CONCLUSION}

The ability to generate 3D models, which accurately reflect real world behaviour, is of great interest to practitioners in tidal stream energy. Visualisation of flow regimes will aid understanding of tidal flow allowing academics and students to better understand and describe behaviour, while this will also assist site developers who can assess a greater number of sites without the need for extensive onsite monitoring as is presently required.

Those designing major components will benefit from models which can show blade and support structure loading conditions, allowing for design and reliable simulations without extensive physical validation which is both costly and time consuming.

Site developers will be able to model many alternative array configurations using realistic and robust CFD models to establish optimal array configuration at each specific site. This will be a compromise between maximum efficiency of each individual turbine versus the output from the entire array and the acceptable in service loading on turbines.
In the future both academia and industry will benefit from robust, reliable models which accurately map out a 3D environment representing a potential tidal stream site. Greater understanding of the practicalities will lead to innovative solutions to challenges presented by the harsh operating environment and allow divergence of design for turbines and major subcomponents, leading to a competitive supply chain.

The ultimate goal is to reduce costs and enable tidal stream turbines to become cost competitive with other forms of energy. If this is achieved the predictable behaviour of the tides can be exploited and managed to produce vast quantities of firm electrical energy onto the UK national grid over the coming years.

\section{REFERENCES}

[1] Sgobbi, A., Simoes, S., Magagna, D. and Nijs, W, 2015. Assessing the impacts of technology improvements on the deployment of marine energy in Europe with an energy system perspective. Renewable Energy, [e-journal] Vol 89 (2016), pp. 515 - 525.

[2] Waters, S. and Aggidis, G., 2015. Tidal range technologies and state of the art in review. Renewable \& Sustainable Energy Reviews. [e-journal] Vol 59 (2016), pp. $514-529$.

[3] O’Rourke, F., Boyle, F. and Reynolds, A., 2009. Tidal energy update 2009. Applied Energy. [e-journal] Vol 87 (2010), pp. $398-409$.

[4] Cengel, Y., Turner, R. and Cimbala, J., 2008. Fundamentals of Thermal-Fluid Sciences Third Edition in SI Units. 3rd Ed. Singapore: McGraw Hill.

[5] Uihlein, A. and Magagna, D., 2015. Wave and tidal current energy - A review of the current state of research beyond technology. Renewable and Sustainable Energy Reviews, [e-journal] Vol 58 (2016), pp. 1070 - 1081.

[6] European Marine Energy Centre, 2009. Assessment of Tidal Energy Resource - Marine Renewable Energy Guides. London: The Charlesworth Group.

[7] BERR (Department for Business, Enterprise \& Regulatory Reform), 2008. Atlas of UK Marine Renewable Energy Resources. London: APBmer, The Met Office, Proudman Oceanographic Laboratory.

[8] Lalander, E., Thomassen, P. and Leijon, M., 2013. Evaluation of a Model for Predicting the Tidal Velocity in Fjord Entrances. Energies, [e-journal] Vol 6 (2013), pp. 2031 - 2051.

[9] Vennell, R., 2011. Estimating the power potential of tidal currents and the impact of power extraction on flow speeds. Renewable Energy. [e-journal] Vol 36 (2011), pp. 3558 - 3565.

[10] visitmyharbour.com , 2015. Tidal Charts for Spring and Neap tides. Available at: http://www.visitmyharbour.com/tides/

[11] Hardisty, J., 2009. The Analysis of Tidal Stream Power. Chichester: John Wiley \& Sons Ltd. 
[12] Nasa.gov, NASA Jet Propulsion Laboratory - Shuttle Radar Topography Mission SRTM. Available at: http://srtm.usgs.gov/index.php

[13] Kolliatsas, C., Dudziak, G., Schaefer, J. and Myers, N., 2012. Offshore Renewable Energy: Accelerating the deployment of offshore wind, tidal and wave technologies. New York: Earthscan.

[14] Vennell, R., 2012. Exceeding the Betz limit with tidal turbines. Renewable Energy. [e-journal] Vol 55 (2013), pp. $277-285$.

[15] Fairley, I,. Masters, I. and Karunarathna, H. 2015. The cumulative impact of tidal stream turbine arrays on sediment transport in the Pentland Firth. Renewable Energy. [e-journal] Vol 80 (2015), pp. 755 - 769.

[16] Robins, P., Neill, S., Lewis, M. and Ward, S., 2015. Characterising the spatial and temporal variability of the tidal-stream energy resource over the northwest European shelf seas. Applied Energy. [e-journal] Vol 147 (2015), pp. 510 - 522.

[17] Neill, S., Hashemi, M. and Lewis, M., 2015. Tidal energy leasing and tidal phasing. Renewable Energy. [ejournal] Vol 85 (2016), pp. 580 - 597.

[18] Magagna, D. and Uihlein, A., 2015. Ocean energy development in Europe: Current status and future perspectives. International Journal of Marine Energy. [e-journal] Vol 11(2015), pp. 84 - 104. 